\title{
I.UMIRUNC
}

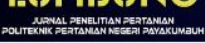

\section{BERBAGAI TARAF PEMBERIAN PUPUK SS DAN PUPUK KANDANG TERHADAP PERTUMBUHAN DAN PRODUKSI TEMBAKAU PAYAKUMBUH}

\author{
Mamang Wahyudi ${ }^{1}$ dan Ardi Sardina Abdullah ${ }^{1}$ \\ ${ }^{1}$ Politeknik Pertanian Negeri Payakumbuh \\ Korespondensi: mamang@yahoo.com
}

\author{
Diterima : :06 Agustus 2019 \\ Disetujui : 30 Agustus 2019 \\ Diterbitkan : 31 Agustus 2019
}

\begin{abstract}
ABSTRAK
Kabupaten Lima Puluh Kota dan Kota Payakumbuh merupakan sentra tanaman tembakau di Sumatera Barat. Pertumbuhan tanaman tembakau yang baik dapat dilakukan dengan menambah unsur hara yang berupa pupuk. Pupuk SS (Superstikpos) merupakan pupuk Mono Amonium Phospat dengan rumus NH4(H2PO4) dimana kandungan Nitrogennya 16\%, Phospor $20 \%$ dan Belerang 12\%. Dosis pupuk yang diberikan pada tembakau Payakumbuh varietas Rudau Gadang dan Rudau Teleng) adalah 92 - $138 \mathrm{~kg} \mathrm{~N} / \mathrm{ha}, 36 \mathrm{kgP} 2 \mathrm{O} 5 / \mathrm{ha}$ dan $46 \mathrm{~kg} \mathrm{~K} 2 \mathrm{O} / \mathrm{ha}$ dimana pemupukan ini dilakukan pada lahan yang sering ditanaman tembakau. Penelitian ini merupakan percobaan faktorial dua faktor 4 x 3 yang disusun menurut Rancangan Acak Kelompok (RAK) dengan 3 kali ulangan. Data hasil pengamatan dianalisis secara statistika dengan menggunakan sidik ragam (uji F) untuk Rancangan Acak Kelompok (RAK). Apabila berbeda nyata, dilanjutkan dengan DMRT pada taraf 5\%. Sebagai data tambahan dilakukan pengujian kadar nikotin pada masing-masing perlakuan. (data diuji dengan atistika). Pemberian pupuk SS dengan dosis $100 \mathrm{~kg} / \mathrm{ha}$ atau $200 \mathrm{~kg} / \mathrm{ha}$ dan pemberian pupuk kandang dosis 30 ton/ha pengaruhnya paling tinggi terhadap Indeks Luas Daun. Pemberian pupuk SS dengan dosis $150 \mathrm{~kg} / \mathrm{ha}$ dan pemberian pupuk kandang dosis 10 ton/ha pengaruhnya paling rendah terhadap Indeks Luas Daun. Pemberian pupuk SS dengan dosis $100 \mathrm{~kg} / \mathrm{ha}$ dan pemberian pupuk kandang dosis 30 ton/ha pengaruhnya paling tinggi terhadap Berat Basah dan Berat Kering daun tembakau. Pemberian pupuk SS dengan dosis $150 \mathrm{~kg} / \mathrm{ha}$ dan pemberian pupuk kandang dosis 10 ton/ha pengaruhnya paling rendah terhadap Berat Basah Daun. Pemberian pupuk SS dengan dosis $250 \mathrm{~kg} / \mathrm{ha}$ dan pemberian pupuk kandang dosis 10 ton/ha pengaruhnya paling rendah terhadap Berat Kering Daun.
\end{abstract}

Kata Kunci: pupuk ss, pupuk kandang, produksi tembakau

\begin{abstract}
Lima Puluh Kota Regency and Payakumbuh City are centers of tobacco plants in West Sumatra. A good growth of tobacco plants can be done by adding nutrients in the form of fertilizer. SS (Superstikpos) fertilizer is Mono Ammonium Phosphate fertilizer with the formula NH4 (H2PO4) where the Nitrogen content is 16\%, Phospor 20\% and Sulfur $12 \%$. The dosage of fertilizer given to Payakumbuh tobacco is Rudau Gadang and
\end{abstract}




\section{I.UMIRUNC}

Rudau Teleng varieties), 92 - $138 \mathrm{~kg} \mathrm{~N} / \mathrm{ha}, 36 \mathrm{kgP} 2 \mathrm{O5} / \mathrm{ha}$ and $46 \mathrm{~kg} \mathrm{K2O/ha}$ where fertilization is carried out on land that is often planted with tobacco. This research was a $4 \times 3$ factorial two factorial experiment arranged according to the Randomized Block Design (RBD) with 3 replications. Observation data were analyzed statistically by using variance ( $F$ test) for the Randomized Block Design (RBD). If significantly different, followed by DMRT at the 5\% level. As additional data, nicotine levels were tested in each treatment. (data tested with statistics). The application of SS fertilizer with a dose of $100 \mathrm{~kg} / \mathrm{ha}$ or $200 \mathrm{~kg} / \mathrm{ha}$ and the provision of manure with a dose of 30 tons / ha has the highest effect on the Leaf Area Index. The application of SS fertilizer at a dose of $150 \mathrm{~kg} / \mathrm{ha}$ and the provision of manure at a dose of 10 tons / ha has the lowest effect on the Leaf Luad Index. The application of SS fertilizer at a dose of $100 \mathrm{~kg} / \mathrm{ha}$ and the provision of manure at a dose of 30 tons / ha has the highest effect on the Wet Weight and Dry Weight of tobacco leaves. The application of SS fertilizer at a dose of $150 \mathrm{~kg} /$ ha and the administration of manure at a dose of 10 tons / ha has the lowest effect on Leaf Wet Weight. The application of SS fertilizer at a dose of $250 \mathrm{~kg} / \mathrm{ha}$ and the administration of manure at a dose of 10 tons / ha has the lowest effect on leaf dry weight.

Keywords: ss fertilizer, manure, tobacco production

\section{PENDAHULUAN}

Kabupaten Lima Puluh Kota dan Kota Payakumbuh merupakan sentra tanaman tembakau di Sumatera Barat. Perincian produksi tembakau tiap Kecamatan di Kabupaten Lima Puluh Kota sebagai berikut: Kecamatan Suliki sebesar 0,670 ton/ha, Kecamatan Gunung Mas sebesar 0,671 ton/ha, Kecamatan Guguk sebesar 0,699 ton/ha, Kecamatan Payakumbuh sebesar 0,782 kg/ha, Kecamatan Luhak sebesar 0,659 ton/ha. Rata-rata produksi tembakau payakumbuh masih rendah yaitu 0,701 ton/ha., bila dilihat rata-rata produksi nasional untuk tanaman tembakau hanya mencapai 0,8 ton/ha, sedangkan simbabwe sebesar 1,8 ton/ha, Jepang mencapai 3,7 ton/ha oleh sebab itu potensi untuk meningkatkan tembakau di Indonesia masih terbuka lebar khususnya tembakau Payakumbuh (Disbun kabupaten 50 Kota,1999).

Pertumbuhan tanaman tembakau yang baik dapat dilakukan dengan menambah unsur hara yang berupa pupuk. Pupuk yang digunakan adalah pupuk yang mengandung NPK, disamping itu ada unsur lain yang terikut dalam pupuk yaitu unsur Belirang. Nitrogen berperan meningkatkan pertumbuhan vegetatip seperti batang, daun, perakaran dan pembentukan sel-sel baru, sedangkan Phospor berperan untuk pembentukan bunga, buah dan biji. Jenis pupuk nitrogen dan Phospor dapat diperoleh dalam bentuk Amophos yaitu SS (Bambang Cahyono, 1998; Sarief, 1985). 


\section{I.UMIRUNC}

Pupuk SS (Superstikpos) merupakan pupuk Mono Amonium Phospat dengan rumus NH4(H2PO4) dimana kandungan Nitrogennya 16\%, Phospor 20\% dan Belirang 12\%. Pupuk Amophos ini dengan merek dagang SS (Superstikpos) sudah lama dikenal di Indonesia, diperdagangkan dalam bentuk butiran berwarna abu-abu muda dan sudah lama digunakan pada berbagai tanaman. (Sarief, 1985; Hakim dkk, 1988).

Sarief (1985) dan Soepardi (1987) menyatakan bahwa pupuk Amophos ini dapat menggantikan ZA dan DS mengingat $\mathrm{N}$ dan P2O5 nya tersedia dalam bentuk yang hampir sama dengan ZA dan DS. Menurut Tso (1972), nitrogen merupakan unsur penting yang sangat berpengaruh terhadap pertumbuhan tanaman, produksi dan kualitas tembakau yang dihasilkan. Kandungan kimia daun tembakau sangat dipengaruhi oleh tingkat pemupukan nitrogen dan total unsur hara dalam tanah.

Pengaruh nitrogen terhadap pertumbuhan dan produksi tanaman yaitu pada senyawa organik dalam tanaman misalnya asam-asam amino, asam nucleat, enzimenzim, bahan-bahan yang menyalurkan energi seperti klorofil, ADP, dan ATP. Tanaman tidak melakukan metabolisme bila kekurangan $\mathrm{N}$ untuk bahan-bahan vital tersebut (Suseno, 1974; Salesbury dan Ross, 1995).

Hakim dkk (1986) melaporkan pupuk yang mengandung belerang akan mengefisiensikan pupuk nitrogen dan kalium yang mudah tercuci, disamping itu juga berfungsi untuk mengurangi pengaruh buruk dari klor yang berlebihan. Belerang merupakan unsur essensial bagi pertumbuhan tanaman yaitu sangat diperlukan untuk berbagai reaksi dalam sel hidup, terutama sebagai penyusun asam amino metionin dan sistein. (Suseno, 1974; Salisbury dan Ross, 1992)

Bruckner, (1936) dalam Tso (1972) mengemukakan senyawa nitogen dalam daun tembakau akan memberikan rasa berat, semakin tinggi total nitrogen rasa semakin berat dan pedas sebaliknya bila kandungan nitrogennya rendah rasanya tawar/ringan. Phospat adalah unsur essensial yang diperlukan tanaman untuk pertumbuhan dalam jumlah yang relatip banyak. Pertumbuhan akan terhambat apabila unsur $\mathrm{P}$ kurang tersedia dalam tanah, terlalu lambat tersedia atau tidak diimbangi oleh unsur lainnya (Soepardi, 1983; Hakim dkk, 1988). Phospat adalah unsur essensial yang diperlukan tanaman untuk pertumbuhan dalam jumlah yang relatip banyak. Pertumbuhan akan terhambat apabila unsur $\mathrm{P}$ kurang tersedia dalam tanah, terlalu lambat tersedia atau tidak diimbangi oleh unsur lainnya (Soepardi, 1983; Hakim dkk, 1988). 


\section{I.UMIRUNC}

Soepardi (1983) dan Hakim dkk (1988) menyatakan bahwa tiap jenis tanaman mempunyai kemampuan yang berbeda-beda untuk mendapatkan phospat secukupnya dari tanah. Tanaman muda mengasimilasi phospat dengan cepat, sebagian besar pnospat diambil semasa tanaman masis muda, oleh sebab itu sangatlah penting menyediakan phospat yang larut dalam air pada awal pertumbuhan.

Buckman dan Brady (1969) mengemukaan bahwa peranan phospat terhadap pertumbuhan tanaman sebagai berikut: (1). Berperan terhadap perkembangan akar, terutama akar lateral. (2). Mempercepat pembentukan bunga, buah dan biji. (3). Meningkatkan ketahanan terhadap penyakit. Menurut Henry (1994) pupuk kandang mempunyai sifat yang lebih baik dibanding pupuk alam dan pupuk buatan yaitu:

1. Sebagai humus (bunga tanah) yang merupakan zat-zat organis yang terdapat dalam tanah.

2. Sebagai sumber hara Nitrogen, Phospor dan Kalium yang amat penting bagi pertumbuhan dan perkembangan tanaman.

3. Menaikkan daya menahan air (water capasity), sehingga air hujan tidak langsung mengalir ketempa yang rendah tetapi meresap ke dalam tanah.

4. Banyak mengandung mikroorganisme yang berfungsi menghancurkan sampah-sampah yang ada dalam tanah sehingga berguna untuk tanaman,

Menurut Tisdale dan Nelson (1965) dalam Sarief (1985), komposisi dari pupuk kandang adalah 0,5\% N, 0,25 \% P2O5, 0,5\% K2O. Pupuk kandang disamping mengandung unsur makro $\mathrm{N}, \mathrm{P}, \mathrm{K}, \mathrm{Ca}, \mathrm{Mg}$, juga mengandung unsur mikro seperti tembaga, mangan, coper dan boron. Pupuk kandang yang berasal dari kotoran sapi mengandung 0,40\% N, 0,20\% P2O5, 0,10\% K2O dan unsur mikro. Kotoran sapi seberat 7,5-ton segar setelah dibiarkan 2 bulan (matang) akan diperoleh seberat 5 ton.

Dosis pupuk yang diberikan pada tembakau Payakumbuh varietas Rudau Gadang dan Rudau Teleng) adalah 92 - 138 kg N/ha, 36 kgP2O5 /ha dan 46 kg K2O/ha dimana pemupukan ini dilakukan pada lahan yang sering ditanaman tembakau.

\section{METODE PENELITIAN}

\section{Tempat dan Waktu}

Penelitian ini telah dilaksanakan di Kebun Percobaan Politeknik Pertanian Universitas Andalas, Tanjungpati, Kabupaten Lima Puluh Kota dengan ketinggian tempat kira-kira 500 m dari permukaan laut. Kemiringan lahan $0-2 \%$, suhu maksimum 


\section{I.UMIRUNC}

$30^{\circ} \mathrm{C}-32^{\circ} \mathrm{C}$, suhu minimum $25^{\circ}-27^{\circ} \mathrm{C}$, kelembaban udara $60-80 \%$, curah hujan $2000-2500 \mathrm{~mm} /$ tahun, jenis tanah Alluvial dengan tekstur lempung sampai lempung berdebu, struktur tanah gembur sampai remah, $\mathrm{pH}$ tanah 5,0 - 5,6. Pelaksanaan penelitian dimulai pada bulan September 2010 s/d bulan Desember 2010.

\section{Bahan dan Alat}

Bahan-bahan yang digunakan dalam penelitian ini adalah lahan tanam ukuran 15 m x 75 m, Bibit tembakau varietas Rudau Gadang, pupuk SS, pupuk Kandang, dithane M 45, thiodan, curater, pupuk kandang, seng plat. Adapun alat-alat yang diperlukan adalah cangkul, koret, parang, knapsack sprayer, meteran, timbangan, gembor, timba/ember plastik, pisau rajang, alat rajangan, samir, alat tulis dan buku tulis.

\section{Metode Penelitian}

Penelitian ini merupakan percobaan faktorial dua faktor $4 \times 3$ yang disusun menurut Rancangan Acak Kelompok (RAK).

Faktor pertama adalah dosis pupuk SS yang terdiri dari 4 taraf yaitu:

$\mathrm{S} 1$ = Pemberian pupuk SS sebanyak $100 \mathrm{~kg} / \mathrm{ha}$ (5 gram/tanaman)

$\mathrm{S} 2=$ Pemberian pupuk SS sebanyak $150 \mathrm{~kg} / \mathrm{ha}$ (7,5 gram/tanaman)

S3 = Pemberian pupuk SS sebanyak $200 \mathrm{~kg} / \mathrm{ha}$ (10 gram/tanaman)

S4 = Pemberian pupuk SS sebanyak $250 \mathrm{~kg} / \mathrm{ha}$ (12,5 gram/tanaman).

Faktor kedua adalah pemangkasan yang terdiri dari 3 taraf yaitu:

$\mathrm{K} 1=$ Pemberian pupuk Kandang sebanyak 10 ton/ha $(0,5 \mathrm{~kg} / \mathrm{tanaman})$

$\mathrm{K} 2$ = Pemberian pupuk Kandang sebanyak 20 ton/ha $(1 \mathrm{~kg} / \mathrm{tanaman})$

K3 = Pemberian pupuk Kandang sebanyak 30 ton/ha (1,5 kg/tanaman)

Percobaan ini dilakukan dengan 3 ulangan sehingga keseluruhannya terdapat 36unit percobaan. Setiap unit percobaan terdapat 21 tanaman sehingga terdapat 756 tanaman, dengan jumlah sampel pengamatan per unit percobaan 5 tanaman.

Data hasil pengamatan dianalisis secara statistika dengan menggunakan sidik ragam (uji F) untuk Rancangan Acak Kelompok (RAK). Apabila berbeda nyata, dilanjutkan dengan DMRT pada taraf 5\%. Sebagai data tambahan dilakukan pengujian kadar nikotin pada masing-masing perlakuan. (data diuji dengan atistika). 


\section{I.UMIRUNC}

\section{Pelaksanaan Percobaan}

a. Pengolahan tanah dan penaman tembakau

Pengolahan tanah dilakukan $3 \mathrm{kali}$, pengolahan tanah pertama dengan traktor. Pengolahan tanah ke dua dan ke tiga dengan cangkul dimana selang waktu pengolahan masing-masing 1 minggu, setelah itu dilakukan pembuatan plot dengan ukuran satu plot percobaan $3 \mathrm{~m}$ x 3,5 m. Jarak tanam yang digunakan yaitu $50 \mathrm{~cm} \times$ $100 \mathrm{~cm}, 1$ minggu sebelum penanaman dilakukan pemupukan dengan pupuk kandang dosis sesuai perlakuan.

b. Penyiraman

Penyiraman dilakukan pada saat tanam sampai dengan umur 7 HST, memakai air dengan alat gembor.

c. Pemupukan

Pupuk ZK diberikan 7 HST dengan dosis $100 \mathrm{~kg}$ ha-1, pupuk SS diberikan 2 kali yaitu setengah dosis pada 7 HST dan setengah dosis pada umur 30 HST sesuai perlakuan dan pupuk kandang diberikan saat tanam sesuai perlakuan.

d. Penyulaman

Penyulaman dilakukan umur 7 HST, dengan menanam bibit yang telah disediakan untuk penyulaman.

e. Pendangiran dan Penyiangan.

Pendangiran dan penyiangan untuk tanaman tembakau dilakukan 3 kali yaitu pada umur 15 HST, 30 HST dan 45 HST.

f. Pengendalian hama dan penyakit.

Serangan hama dapat dicegah dengan penyemprotan thiodan konsentrasi $1 \mathrm{cc} / \mathrm{lt}$ air, untuk mencegah serangan penyakit dilakukan penyemprotan dithane M 45 dengan konsentrasi 2 gram/lt air, selang waktu penyemprotan 1 minggu 2 kali. Pemberian curater digunakan untuk mencegah serangan ulat tanah yang dilakukan saat tanam dengan dosis 1 gram per tanaman.

g. Pemangkasan pucuk dan tunas ketiak daun.

Pemangkasan pucuk dilakukan pada tanaman tembakau berumur 70 HST, sedangkan pemangkasan tunas ketiak daun dilakukan 1 minggu setelah pemangkasan pucuk dan selang waktu pemangkasan tunas ketiak daun 1 minggu sekali. 


\section{I.UMIBUNG}

h. Panen

Panen dilakukan pada umur 60 HST, berdasarkan kemasakan daun. Pembagian daun adalah 4 helai daun tapak, $6-8$ helai daun pengisi dan $8-10$ helai daun kulit.

i. Pengolahan hasil tembakau

Daun tembakau dipanen lalu diadakan sortasi daun terus ibu tulang daun dibuang lalu digulung dan diperam, setelah itu dibongkar lalu digulung sesuai dengan ukuran alat rajangan lalu dirajang, hasil rajangan dipapar diatas samir dan dijemur setelah kering disemprot dengan cairan yaitu campuran daun tembakau, air dan gula tebu lalu dijemur lagi dan seterusnya bisa disimpan atau dijual langsung.

\section{Pengamatan}

Pengamatan meliputi pajang daun rata-rata $(\mathrm{cm})$, Lebar daun rata-rata $(\mathrm{cm})$, Berat segar daun rata-rata (gram). Berat kering daun rata-rata (gram).

1. Panjang daun rata-rata $(\mathrm{cm})$

Pengamatan panjang daun dilakukan padasetiap kali panen dan dipilih daun yang paling panjang per tingkat daun. Cara pengukurannya dari pangkal helaian daun ke ujung daun.

2. Lebar daun rata-rata $(\mathrm{cm})$.

Pengamatan lebar daun dilakukan pada setiap kali panen dan dipilih daun yang Paling lebar per tingkat daun. Cara pengukurannya dari bagian daun yang terlebar dari tepi ke tepi berikutnya.

2. Luas daun $(\mathrm{cm} 2)$

Pengamatan luas daun dengan rumus: Panjang x Lebar x k $(0,68)$

4. Berat segar daun rata-rata $(\mathrm{cm})$

Pengamatan berat segar daun dilakukan pada saat daun dipanen, lalu beratnya langsung ditimbang per tanaman.

5. Berat kering daun rata-rata $(\mathrm{cm})$

Pengamatan berat kering daun dilakukan pada seluruh daun per tanaman dengan cara mengeringkan daun segar tadi. Daun disujen dan digantung disamping rumah kemudian dikeringanginkan sampai Ibu tulang daun kering, lalu ditimbang beratnya per tanaman. 


\section{I.UMIRUNC}

\section{HASIL DAN PEMBAHASAN}

\section{A. Indeks luas daun tembakau (cm2)}

Hasil perhitungan dengan uji F pada taraf 5\% tentang dosis pemberian pupuk SS dan dosis pemberian pupuk kandang terhadap Indeks luas daun terdapat interaksi, tetapi pengaruh tunggal dosis pemberian pupuk kandang dan pupuk SS tidak berbeda nyata. Hasil uji lanjut dikemukakan pada tabel 1 di bawah ini.

Tabel 1. Indeks luas daun tembakau $(\mathrm{cm} 2)$ pada berbagai dosis pupuk SS dan dosis pupuk kandang.

\begin{tabular}{|l|c|c|c|c|}
\hline \multirow{2}{*}{$\begin{array}{l}\text { Dosis pupuk } \\
\text { Kandang (Ton/ha) }\end{array}$} & \multicolumn{4}{|c|}{ Dosis pupuk SS (kg/ha) } \\
\cline { 2 - 5 } & 100 & 150 & 200 & 250 \\
\hline Dosis PK 10 & $412,46 \mathrm{~A}$ & $314,74 \mathrm{~A}$ & $361,75 \mathrm{~A}$ & $402,97 \mathrm{~A}$ \\
& $\mathrm{a}$ & $\mathrm{a}$ & $\mathrm{a}$ & $\mathrm{a}$ \\
\hline Dosis PK 20 & $413,31 \mathrm{~A}$ & $354,26 \mathrm{~A}$ & $335,11 \mathrm{~A}$ & $356,67 \mathrm{~A}$ \\
& $\mathrm{a}$ & $\mathrm{a}$ & $\mathrm{a}$ & $\mathrm{a}$ \\
\hline Dosis PK 30 & $422,60 \mathrm{~B}$ & $344,34 \mathrm{~A}$ & $420,81 \mathrm{~B}$ & $382,84 \mathrm{~A}$ \\
& $\mathrm{~b}$ & $\mathrm{a}$ & $\mathrm{b}$ & $\mathrm{a}$ \\
\hline
\end{tabular}

Angka-angka pada baris yang sama yang diikuti oleh huruf besar yang sama dan angka-angka pada kolom yang sama yang diikuti oleh huruf kecil yang sama tidak berbeda nyata pada uji DNMRT pada taraf 5\%.

Tabel 1 menunjukkan bahwa pemberian pupuk SS dengan dosis $100 \mathrm{~kg} / \mathrm{ha}$ dan $200 \mathrm{~kg} / \mathrm{ha}$, dengan pemberian pupuk kandang dosis 30 ton/ha akan meningkatkan Indeks Luas daun tembakau, sedangkan pada pemberian pupuk SS dengan dosis 150 $\mathrm{kg} / \mathrm{ha}$ dan dosis pupuk kandang 10 ton/ha menurunkan Indeks Luas daun.

Hasil pengamatan parameter pertumbuhan tanaman tembakau yaitu Indeks luas daun memperlihatkan bahwa pada pemberian pupuk SS dengan dosis $100 \mathrm{~kg} / \mathrm{ha}$ atau $200 \mathrm{~kg} / \mathrm{ha}$ dikombinasikan dengan pemberian pupuk kandang 30 ton/ha menunjukkan pertumbuhan yang paling baik. Kenyataan ini disebabkan nitrogen merupakan unsur penting yang sangat berpengaruh terhadap pertumbuhan tanaman, produksi dan kualitas tembakau yang dihasilkan. Kandungan kimia daun tembakau sangat dipengaruhi oleh tingkat pemupukan nitrogen dan total unsur hara dalam tanah. (Tso, 1972).

Belerang merupakan unsur essensial bagi pertumbuhan tanaman yaitu sangat diperlukan untuk berbagai reaksi dalam sel hidup, terutama sebagai penyusun asam amino metionin dan sistein. (Suseno, 1974; Salisbury dan Ross, 1992) 


\section{I.UMIRUNC}

Phospat adalah unsur essensial yang diperlukan tanaman untuk pertumbuhan dalam jumlah yang relatip banyak. Pertumbuhan akan terhambat apabila unsur $\mathrm{P}$ kurang tersedia dalam tanah, terlalu lambat tersedia atau tidak diimbangi oleh unsur lainnya (Soepardi, 1983; Hakim dkk, 1988).

\section{B. Berat basah daun tembakau (gram)}

Hasil perhitungan dengan uji $\mathrm{F}$ pada taraf 5\% tentang dosis pemberian pupuk SS dan dosis pemberian pupuk kandang terhadap Berat Basah daun tembakau terdapat interaksi, tetapi pengaruh tunggal dosis pemberian pupuk kandang dan pupuk SS tidak berbeda nyata. Hasil uji lanjut dikemukakan pada tabel 2 dibawah ini.

Tabel 2. Berat basah daun tembakau (gram) pada berbagai dosis pupuk SS dan dosis pupuk kandang.

\begin{tabular}{|l|c|c|c|c|}
\hline \multirow{2}{*}{$\begin{array}{l}\text { Dosis pupuk } \\
\text { Kandang (Ton/ha) }\end{array}$} & \multicolumn{4}{|c|}{ Dosis pupuk SS (kg/ha) } \\
\cline { 2 - 5 } & 100 & 150 & 200 & 250 \\
\hline Dosis PK 10 & $284,37 \mathrm{~A}$ & $231,56 \mathrm{~A}$ & $281,67 \mathrm{~A}$ & $277,29 \mathrm{~A}$ \\
& $\mathrm{a}$ & $\mathrm{a}$ & $\mathrm{a}$ & $\mathrm{a}$ \\
\hline Dosis PK 20 & $254,23 \mathrm{~A}$ & $277,39 \mathrm{~A}$ & $265,00 \mathrm{~A}$ & $287,50 \mathrm{~A}$ \\
& $\mathrm{a}$ & $\mathrm{a}$ & $\mathrm{a}$ & $\mathrm{a}$ \\
\hline Dosis PK 30 & $319,79 \mathrm{~B}$ & $267,82 \mathrm{~A}$ & $288,33 \mathrm{~A}$ & $297,40 \mathrm{~A}$ \\
& $\mathrm{~b}$ & $\mathrm{a}$ & $\mathrm{a}$ & $\mathrm{a}$ \\
\hline
\end{tabular}

Angka-angka pada baris yang sama yang diikuti oleh huruf besar yang sama dan angka-angka pada kolom yang sama yang diikuti oleh huruf kecil yang sama tidak berbeda nyata pada uji DNMRT pada taraf 5\%.

\section{Berat kering daun tembakau (gram)}

Hasil perhitungan dengan uji $\mathrm{F}$ pada taraf 5\% tentang dosis pemberian pupuk SS dan dosis pemberian pupuk kandang terhadap Berat Kering daun tembakau terdapat interaksi, tetapi pengaruh tunggal dosis pemberian pupuk kandang dan pupuk SS tidak berbeda nyata. Hasil uji lanjut dikemukakan pada tabel 3.

Tabel 2 dan Tabel 3 menunjukkan bahwa pemberian pupuk SS dengan dosis 100 $\mathrm{kg} / \mathrm{ha}$ dan pemberian pupuk kandang dosis $30 \mathrm{~kg} / \mathrm{ha}$ akan meningkatkan berat basah dan berat kering daun tembakau, sedangkan pada pemberian pupuk SS dengan dosis 250 $\mathrm{kg} / \mathrm{ha}$ dan pupuk kandang 10 ton/ha menurunkan berat basah dan berat kering daun tembakau. 


\section{I.UMIRUNC}

Tabel 3. Berat kering daun tembakau (gram) pada berbagai dosis pupuk SS dan dosis pupuk kandang

\begin{tabular}{|l|c|c|c|c|}
\hline \multirow{2}{*}{$\begin{array}{l}\text { Dosis pupuk } \\
\text { Kandang (Ton/ha) }\end{array}$} & \multicolumn{4}{|c|}{ Dosis pupuk SS (kg/ha) } \\
\cline { 2 - 5 } & 100 & 150 & 200 & 250 \\
\hline Dosis PK 10 & $42,66 \mathrm{~A}$ & $34,73 \mathrm{~A}$ & $42,25 \mathrm{~A}$ & $34,09 \mathrm{~A}$ \\
& $\mathrm{a}$ & $\mathrm{a}$ & $\mathrm{a}$ & $\mathrm{a}$ \\
\hline Dosis PK 20 & $38,14 \mathrm{~A}$ & $34,11 \mathrm{~A}$ & $39,75 \mathrm{~A}$ & $43,13 \mathrm{~A}$ \\
& $\mathrm{a}$ & $\mathrm{a}$ & $\mathrm{a}$ & $\mathrm{a}$ \\
\hline Dosis PK 30 & $47,97 \mathrm{~B}$ & $40,17 \mathrm{~A}$ & $43,25 \mathrm{~A}$ & $45,94 \mathrm{~A}$ \\
& $\mathrm{~b}$ & $\mathrm{a}$ & $\mathrm{a}$ & $\mathrm{a}$ \\
\hline
\end{tabular}

Angka-angka pada baris yang sama yang diikuti oleh huruf besar yang sama dan angka-angka pada kolom yang sama yang diikuti oleh huruf kecil yang sama tidak berbeda nyata pada uji DNMRT pada taraf $5 \%$.

Hasil pengamatan produksi tanaman tembakau yaitu berat basah dan berat kering daun tembakau memperlihatkan bahwa pada pemberian pupuk SS dengan dosis $100 \mathrm{~kg} / \mathrm{ha}$ dikombinasikan dengan pemberian pupuk kandang 30 ton/ha menunjukkan produksi paling baik. Kenyataan ini disebabkan pengaruh nitrogen terhadap produksi tanaman tembakau yaitu pada senyawa organik dalam tanaman misalnya asam-asam amino, asam nukleat, enzim-enzim, bahan-bahan yang menyalurkan energi seperti klorofil, ADP dan ATP. Tanaman tidak melakukan metabolisme bila kekurangan N (Suseno, 1974; Salesbury dan Ross, 1995).

\section{KESIMPULAN}

1. Pemberian pupuk SS dengan dosis $100 \mathrm{~kg} / \mathrm{ha}$ atau $200 \mathrm{~kg} / \mathrm{ha}$ dan pemberian pupuk kandang dosis 30 ton/ha pengaruhnya paling tinggi terhadap Indeks Luas Daun.

2. Pemberian pupuk SS dengan dosis $150 \mathrm{~kg} / \mathrm{ha}$ dan pemberian pupuk kandang dosis 10 ton/ha pengaruhnya paling rendah terhadap Indeks Luas Daun.

3. Pemberian pupuk SS dengan dosis $100 \mathrm{~kg} / \mathrm{ha}$ dan pemberian pupuk kandang dosis 30 ton/ha pengaruhnya paling tinggi terhadap Berat Basah dan Berat Kering daun tembakau.

4. Pemberian pupuk SS dengan dosis $150 \mathrm{~kg} / \mathrm{ha}$ dan pemberian pupuk kandang dosis 10 ton/ha pengaruhnya paling rendah terhadap Berat Basah Daun.

5. Pemberian pupuk SS dengan dosis $250 \mathrm{~kg} / \mathrm{ha}$ dan pemberian pupuk kandang dosis 10 ton/ha pengaruhnya paling rendah terhadap Berat Kering Daun. 


\section{I.UMIBUNG}

\section{DAFTAR PUSTAKA}

Bambang Cahyono. 1998. Tembakau, Budidaya dan Analisis usaha tani. Kanisius Yogyakarta.

Buckman, H.O and N.C. Brady. 1974. The nature and properties of soil. The Mac Millan Publ. Co. Inc. New York.

Collins. W.K. and S.N. Hawks. 1993. Principle of flue cured tobacco production. N.C. State University.

Disbun Kabupaten 50 Kota. 1999. Penggunaan lahan untuk perkebunan tembakau rakyat beserta produksinya per hektar per kecamatan.

Frank. B. Salisbury \& Cleon. W. Ross. 1992. Fisiologi Tumbuhan. ITB. Bandung.

Hari Suseno. 1974. Fisiologi tumbuhan. Metabolisme dasar dan beberapa aspeknya. Departemen Botani. FAPERTA, IPB. Bogor.

Hartana. 1979. Budidaya tembakau Cerutu I masa pra panen. Cetakan ke 2. Balai Penelitian Perkebunan. Jember.

Hawks, S.N and W.K. Collins. 1983. Principles of Flue Cured. Tobacco Production. N.C. State University.

Nurhayati Hakim, Go ban hong, Ali Munawar, Ghaffar Amrah, Mamat Anwar Pulung, Lubis. A.M. dan Yusuf Nyakpa. 1988. Kesuburan tanah. Universitas Lampung.

Saifuddin Sarief. 1985. Kesuburan tanah. cetakan pertama. Pustaka Buana, Bandung.

Soepardi, G. 1987. Dasar-dasar pemupukan berimbang. Bahan kursus alih teknologi pemupukan berimbang untuk tanaman perkebunan. 25-27 Nopember. BALITTAS. Malang.

Tso, T, C. 1972. Physiology and biochemestry of tobacco plant. Dowden, Hutcchin Son \& Ross. Inc. Strosburg. 